\title{
ARCHIVO BOLAÑO 1977-2003: EL ARCHIVO DE UN ESCISIONISTA
}

\author{
BOLAÑO ARCHIVE 1977-2003: THE ARCHIVE OF A SCISSIONIST
}

\author{
Alejandra Oyarce Orrego \\ Universidad de Concepción. Concepción, Chile \\ alejandraoyarce@udec.cl
}

Recibido: 24.02.2014. Aceptado: 09.04.2014.

Resumen: En este artículo se realiza una aproximación al "Archivo Bolaño 19772003”, como exposición y como libro-catálogo. El análisis del libro y la experiencia directa con la exposición permiten reafirmar el carácter subversivo, escisionista, del proyecto de escritura y del proyecto vital de Roberto Bolaño, frente a la dimensión de lo falso y a la crisis del tiempo; es decir, en oposición al nihilismo cumplido. Todo lo cual se traduce en una búsqueda de nuevas formas para la literatura y, así, la continuidad de ella.

Palabras clave: Archivo Bolaño, escisionista, nihilismo, literatura chilena.

Abstract: This paper presents an approach to "Bolaño Archive 1977-2003" as an exhibition and as a book-catalog. The analysis of the book and the direct experience of the exhibition make it possible to reaffirm the subversive, scissionist, character of the writing project and life project of Roberto Bolaño, in reaction to the dimension of falsehood and the crisis of time, i.e., in opposition to nihilism fulfilled, all of which translates into a search for new forms of literature and thus its continuity.

Key words: Bolaño, scissionist, nihilism, Chilean literature.

$\mathrm{D}$ ESDE QUE RoBerTo Bolaño obtiene los primeros reconocimientos por su producción literaria y, sobre todo, en forma posterior a su muerte, han aparecido una serie de publicaciones en torno a su vida y su obra. En este sentido, hay una manifiesta variedad en términos de tendencia y pro- 
fundidad; sin embargo, más allá de nuestra impresión crítica, nos parece que las diversas aproximaciones aportan elementos a la reflexión principal y reafirman la centralidad de la obra de Bolaño, cuya existencia y proyecto literario están marcados por el desplazamiento desde la marginalidad inicial, que va acompañada del rechazo editorial, hasta la notoriedad que logra hacia el final de su vida. Así, destaca en el presente como uno de los escritores que más atención crítica concentra y cuya obra se proyecta hacia el futuro.

La atracción que genera la vida del escritor y el interés global por su obra, parte de ella todavía inédita y cuyos manuscritos se exhiben en el "Archivo Bolaño 1977-2003", confirman la importancia de su figura y su legado. A su vez, contribuye a explicar la realización de la actividad que abordamos en este trabajo y, en alguna medida, ayuda a entender la polémica que un evento de estas características conlleva.

Por una parte, los herederos de Bolaño, encabezados por Carolina López, así como también los organizadores del Archivo, sostienen que, junto con rendir un homenaje, la principal motivación para la realización de esta actividad está en mostrar directamente el trabajo del escritor, posibilitar el contacto visual con su escritura y, de este modo, explicitar la pasión y dedicación exclusiva de Bolaño a su proyecto de escritura. Estos planteamientos son recogidos por la prensa, que da cobertura a los distintos homenajes organizados con motivo del décimo aniversario de la muerte del escritor y, especialmente, a propósito del Archivo. En este contexto, citamos la nota "El Bolaño más íntimo", publicada en "Artes y Letras" de El Mercurio (10 de marzo de 2013: E 4). Aquí, Macarena García recoge la versión de la viuda de Bolaño, quien enfatiza que, a través de la exposición de los cuadernos manuscritos originales, se busca "mostrar cuánto trabajó Roberto para convertirse en Bolaño" (2013: E4). Al mismo tiempo, se enfatiza que para Carolina López, a través del Archivo se pretende entregar una imagen más íntima del escritor, como padre de familia y esposo, para desmitificar su nombre. Asimismo, la exposición permite, a juicio de la viuda, mostrar al escritor en sus aspectos más cotidianos y destacar que con un esfuerzo sistemático y con trabajo real entregó su vida a la literatura. En este sentido, el testimonio material de aquello reposa en las más de 14 mil páginas escritas, por lo que, según López, "catalogar sus escritos ha tomado siete años" (2013: E4).

Por otra parte, existen otras visiones que han sido difundidas por la 
prensa y que difieren respecto a las motivaciones que respaldarían la realización del "Archivo Bolaño". En este caso recogemos la perspectiva crítica de Ignacio Echevarría, quien asume una postura notoriamente divergente, pues tiende a discutir la validez de la exposición y a poner en tela de juicio las razones y finalidades enfatizadas anteriormente por López, a quien considera más bien decidida a disipar las sospechas de codicia que han recaído sobre ella, y a replicar las reticencias con que han sido recibidos los dos últimos libros de Bolaño, refiriéndose con ello a la publicación póstuma de El Tercer Reich (2010) y Los sinsabores del verdadero policía (2011), obras que, a juicio del crítico, se presentan con ambigüedades que escapan del plan original del escritor. Así, en la nota "El Archivo Bolaño" publicada en "Artes y Letras" de El Mercurio (31 de marzo de 2013: E 14), Echevarría cuestiona directamente la exhibición del Archivo, tal como se aprecia a continuación:

La exhibición del archivo -algo que no hubiera hecho ninguna gracia a Bolaño- tiene todos los visos de ser una demostración de fuerza, un alarde de trofeos, una manera de enseñar las cartas dejando claro quién lleva la mano. Pero un archivo privado, cerrado a la libre consulta de investigadores y estudiosos, no es garante de nada. Y el secretismo de Carolina López, la severa fiscalización que hace del empleo de los textos de Bolaño, el celo acusador con que persigue iniciativas de exploración y de divulgación de su obra que escapan a su estricta contabilidad, no inspiran demasiada tranquilidad. El arbitrario boicot que ha impuesto a la divulgación internacional de un libro tan emocionante y valioso como Bolaño por sí mismo (Ediciones UDP, 2006), magníficamente armado por Andrés Braithwaite, resulta indicativo (2013: E14).

Como se advierte en el fragmento anterior, además de divergir respecto a las motivaciones y finalidades de la exposición, Ignacio Echevarría se refiere críticamente al Archivo en sí, enfatizando aspectos que le parecen cuestionables, tales como la falta de referentes a los años pasados en México y a las amistades arraigadas durante la juventud. Asimismo, ve como un equívoco, o al menos como una limitación, la escasa presencia de elementos que den cuenta de la relación del escritor con Chile. En la misma columna, enfatiza que esto podría dar cuenta de un proceso intencional de borradura de huellas y ocultaciones que, a juicio del crítico, contribuiría a consolidar una versión oficial, doméstica, de la vida de Bolaño. 
$\mathrm{Al}$ respecto, cabe notar que, a pesar de la controversia en relación a este tema específico y pese a que Echevarría no figura entre los colaboradores del Archivo, su relevancia como conocedor de la obra del autor resulta innegable. Así lo permite mostrar el que en el libro-catálogo Archivo Bolaño (2013), específicamente, en el texto de Vila-Matas, se remite a una de las ideas claves que el crítico ha desarrollado en relación al ejercicio literario de Roberto Bolaño y a la importancia que adquieren los largos años de trabajo silencioso y anónimo en los que Bolaño logra dar forma a su proyecto.

No obstante, más allá de las opiniones que la exposición genera y traspasando las polémicas que surgen sobre la finalidad y aporte de dicha actividad $^{1}$, consideramos que resulta interesante entrar en el Archivo, acceder a él, para hablar desde la observación directa y el conocimiento empírico.

La hipótesis que planteamos es que la aproximación reflexiva y directa al "Archivo Bolaño" permite reafirmar el carácter subversivo, "escisionista", del proyecto vital y de escritura de Roberto Bolaño, frente a la dimensión de lo falso y a la crisis del tiempo; es decir, en oposición al nihilismo cumplido.

Respecto a la metodología ${ }^{2}$, desde la observación directa del Archivo

${ }^{1}$ Junto con los textos de García (2013) y Echevarría (2013), consignamos también la nota de Pedro Pablo Guerrero, "Festín para lectores de Bolaño" (2013: E 14), en "Artes y Letras" de El Mercurio, en que se da cuenta de la publicación Archivo Bolaño 1977-2003, pues contribuye a dejar constancia de la polémica que rodea a la exposición, sobre todo en relación a las diferencias de opinión entre López y Echevarría. Asimismo, se entrega una descripción del libro-catálogo que acompaña a la exposición. Entre otras actividades realizadas con motivo del fallecimiento del escritor y como forma de constatar un interés global en su figura y su obra. Cabe destacar, además, la realización del Congreso literario "Estrella distante", organizado por la Dirección de Investigación y Postgrado de la Facultad de Letras de la Pontificia Universidad Católica de Chile, el Departamento de Literatura de la Universidad de Playa Ancha y la Carrera de Licenciatura en Letras de la Universidad Andrés Bello, que se realiza en las ciudades de Santiago, Viña del Mar y Valparaíso, los días 15,17 y 18 de julio de 2013.

${ }^{2}$ Seguimos aquí el concepto de corte estratigráfico, a partir de un trabajo desarrollado por Michel Houellebecq, específicamente en uno de los ensayos de su libro Intervenciones (2011). Aquí explica, en términos técnicos, en qué consiste este procedimiento de la geología, que aplicado a la agronomía y que, extrapolado a la literatura le permite observar, sintetizar y explicar la escritura de Robbe-Grillet, sin quedar entrampado en la magnitud del objeto, pues no busca un acercamiento a la totalidad de su escritura en términos totalizadores, sino que privilegia el trabajo a partir de fragmentos específicos. En este sentido, la metodología nos parece adecuada para nuestro objeto, pues tampoco nos mueve un afán totalizador, en el sentido de intentar abarcar toda la obra de Bolaño de una vez, ni toda la bibliografía existente en torno a ella, sino que optamos por la selección de un determinado segmento, privilegiando la observación directa y el trabajo en profundidad, pero acotadamente. 
como exposición y de la lectura crítica del libro-catálogo que la acompaña, optamos por abordar ambos de manera acotada, privilegiando la fragmentación. La validez de proceder así, privilegiando el estudio de segmentos específicos se refuerza con la reflexión de Bernard-Henri Lévy en diálogo con Michel Houellebecq, en Enemigos públicos (2010), donde se enfatiza que el arte se presenta de manera fundamental en el fragmento: " $\mathrm{El}$ arte, de igual manera, es este verso; es esta página de prosa, un golpe de cincel de Praxíteles o una pincelada de Uccello; es un raccord genial, el "y" a principio de frase de Madame Bovary, el suplemento intelectual que aporta una novela de Philip Roth; es una foto de Richard Avedon; es una página autobiográfica de Gombrowicz, una escena de Esquilo o de Racine; sí, todo esto es mayor, local y definitivamente mayor, incluido en una misma obra de un mismo artista" (2010: 275-276).

En cuanto a la reflexión teórica que contextualiza nuestro trabajo, ésta se fundamenta en las principales ideas que François Meyronnis desarrolla en L'Axe du Néant (2003) sobre la continuidad de la literatura y en el ensayo que Frédéric Badré realiza sobre este pensamiento teórico en el libro L' avenir de la littérature (2003). Asimismo, desde el pensamiento que Jaron Lanier desarrolla en No somos computadoras (2012), en relación a la cultura cibernética en su momento digital y a la importancia que, en este contexto, adquiere la experiencia.

El enfoque antihumano de las tecnologías de la información, el predominio de la mercancía y la hegemonía de la dimensión económica que reduce todo a cifra, a productos de consumo desechables cada vez más a corto plazo, se explican en relación al nihilismo consumado ${ }^{3}$ de fines del siglo XX

\footnotetext{
${ }^{3} \mathrm{El}$ concepto de nihilismo lo abordamos a través de una síntesis que Vicente Serrano Marín actualiza en su artículo: "Nihilismo y fin de la historia. Una mirada sobre la cuestión de la (pos) modernidad” (2007). En él hace prácticamente sinónimos el concepto con posmodernidad. Destaca que el término nihilismo aparece utilizado por primera vez por Jacobi, en su carta a Fitche, en 1799. En su actualización del concepto, realiza una síntesis del pensamiento de Nietzsche y de Heidegger, en relación al pensamiento de Lyotard: "La fórmula de Lyotard parece que es condensar la inversión-conservación del término nihilismo tal como es ejecutado por Nietzsche y Heidegger a partir de Jacobi. En Jacobi, nihilismo era sin más la negación de Dios, a través de la afirmación del sujeto y la razón. En Nietzsche, el nihilismo abarca a Dios y a la razón como una prolongación de aquel, en algo que Heidegger denomina la onto-teología, de cuya "superación" cabía esperar el nuevo Dios, un comienzo absoluto. En Lyotard la posmodernidad aparece finalmente como ese
} 
y principios del siglo XXI, responsable del proceso de deshumanización que se manifiesta en todas las dimensiones del funcionamiento humano, según explica Meyronnis en L'Axe du Néant:

Qu'est-ce qui caractérise le nihilisme? Au plus profond: un certain mépris à l'encontre du Rien, une certaine manière de le tenir pour décevant et sans intérêt. Ce que tu ne peux manier, organiser, ce dont tu ne peux prendre soin, n'est pour lui que songerie creuse et fumigation chimérique - figure du négligeable.

Plus encore que par l'existence des choses concrètes, il est obnubilé par leur "valeur". Il évalue sans arrêt, déterminant ce qui "vaut" le plus et le moins selon une échelle des relations d'équivalence.

Le nihilisme mesure à chaque instant, et ce qui n'est pas mesurable à la seconde est pour lui inévaluable, donc essentiellement inutile (2003: 24).

Meyronnis especifica que el nihilismo cumplido o consumado es lo que define el funcionamiento actual, planetario, en la medida en que el mercado constituye una gigantesca bolsa de valores que circulan sin interrupción y donde la cifra es la dimensión determinante. Esto conduce al vacío extremo, a la asimbolización y bloqueo mental de la especie humana, que el teórico denomina humanoide del nihilismo.

Así, se puede entender la idea del mal como consustancial al ser humano, aspecto que reconocemos como dimensión central en la obra de Bolaño. Lo anterior explicaría los efectos catastróficos para el planeta y para el ser humano, en tanto, colapso y desaparición de las dimensiones de tiempo cronológico y espacio, ejes tradicionales de nuestro pensamiento. Lo que conlleva la imposibilidad de concebir la idea de historia y la consecuente descomposición del campo literario.

No obstante lo anterior y desde los fundamentos teóricos antes referidos, destacamos que la posibilidad de franquear el nihilismo e ir más allá de la parálisis, se produce a partir de una escisión, un desbloqueo que implica una nueva fe en el lenguaje, pero no del lenguaje comunicacional que

lugar del comienzo absoluto, de la modernidad superada, del nihilismo consumado". En nuestra percepción, desde la perspectiva de Meyronnis, el nihilismo correspondería a la visión lineal del tiempo originado en una caída como vector lineal, basado en la sucesión y que tiene como final la muerte o la eternidad. 
es parte de la descomposición, sino a partir del lenguaje poético en el que aguarda una reserva de energía, de cuya liberación y puesta en movimiento se genera la posibilidad de continuidad. Para ello, la literatura ofrece una oportunidad única, si no se concibe como una actividad superficial y utilitaria. En este sentido, un libro importa y es valioso por el pensamiento que él genera y por su fuerza poética, lo cual no es lo que prima en el momento actual en que el mercado intenta hacer de la literatura un elemento desechable más en la industria de la diversión.

Creemos que estas ideas son aplicables para contextualizar, entender y valorar la obra de Roberto Bolaño, más allá de las operaciones del mercado que al detectar un potencial producto rentable, intenta controlarlo y ponerlo en vitrinas y estanterías de gran parte del planeta, con la expectativa de que pasará pronto para ir por otro producto que lo suceda, pero desconociendo lo que en ella se trama. Por el contrario, creemos que la obra de Bolaño pone a la literatura y el lenguaje en el centro, resistiéndose a ser calibrada y continúa imponiéndose cada vez con más fuerza, no sólo por su calidad, sino porque, a nuestro juicio y siguiendo las propuestas de Meyronnis y Badré, busca cambiar nuestro modo de leer y, sobre todo, porque en ella hay una búsqueda intensa de nuevas formas para la literatura ${ }^{4}$. Esa, creemos, sería la jugada maestra.

Por lo tanto, en este sentido nos interesa aproximarnos al Archivo del escritor, focalizándonos en el carácter revolucionario de la escritura de Bolaño, como apuesta por la libertad, donde lo que predomina es el lenguaje con su energía vital y su fuerza poética, movilizando un pensamiento que fluye en su escritura, en sus variantes creativa y crítica, más allá del verso o la prosa, tal como la crítica lo ha detectado.

$\mathrm{Al}$ respecto $\mathrm{y}$, de manera específica, tomamos la idea que Meyronnis desarrolla en el apartado "Note 2 (du «style insurrectionnel» de Guy Debord)" (2003: 296-314), donde destaca que el estilo insurreccional es el que define la fuerza del pensamiento y de la escritura de Debord, puesto

\footnotetext{
${ }^{4}$ En el caso de Bolaño, creemos que esta experiencia extrema con la literatura está en gran medida impulsada por su relación con la enfermedad terminal, lo que explicaría la constante presencia de la muerte que, en su obra y siguiendo a Lyotard, entendemos como pulsión de muerte, concepto que desarrollamos y aplicamos con mayor profundidad en el artículo "Cortes estratigráficos en la crítica y en la obra de Roberto Bolaño" (Oyarce Orrego, 2012: 9-33).
} 
que la poesía aparece como la única dimensión que conserva un espacio de libertad, después de constatar los límites de la "teoría revolucionaria" al convertirse en "ideología revolucionaria"; es decir, también contaminada por lo falso. Por lo tanto, la palabra "revolucionaria" sólo sería vigente si se relaciona con la palabra "poesía" y con un trabajo profundo con el lenguaje poético. Es decir, en los mismos términos que lo plantea Badré al explicitar los objetivos de su revista Ligne de risque:

L'aventure poétique contient virtuellement une dimension révolutionnaire. Celle-ci ne concerne pas que les livres. Elle engage la vie de chacun. Un vrai livre ne fait que donner une FORME à cet engagement (2003: 122).

Por lo tanto, un verdadero escritor es quien se plantea como conspirador, dinamitador del lenguaje, a través de una postura crítica extrema y revitalizada que se levanta contra el dominio de la mercancía y de lo falso, especialmente, en relación al ejercicio de la literatura.

De modo complementario, nuestro trabajo en relación al Archivo se contextualiza en la reflexión que Jaron Lanier plantea en términos críticos, frente a las tecnologías de la información y a la inteligencia artificial, en la medida en que la tecnología postindustrial aparece también como una de las variables que explican el proceso terminal al que llega la literatura. Así, enfatizamos la importancia que adquiere la experiencia real, en el contexto actual, dominado por lo virtual, pues según Lanier no podemos olvidar que "un ordenador ni siquiera existe a menos que una persona lo experimente. Puede que haya una masa caliente de silicio estampado atravesado por corrientes eléctricas, pero los bits no significan nada sin una persona culta que los interprete" (2012: 44). En este sentido, Lanier agrega que: "Un archivo, en un disco duro contiene sin duda información que existe objetivamente. El hecho de que los bits sean discernibles en lugar de estar revueltos en una masa confusa -tal como el calor revuelve las cosas- es lo que los convierte en bits. Pero, si bien los bits pueden guardar un significado potencial, únicamente pueden hacerlo si son experimentados por alguien. Cuando eso sucede, se desarrolla una comunión cultural entre el que acumula los bits y el que los recupera. La experiencia es el único proceso que puede desalienar la información" (47).

Nos quedamos con esta última idea de Lanier y desde esta base teóri- 
ca, consideramos que la revisión directa de los materiales que conforman la exposición del "Archivo Bolaño” y el análisis crítico del libro-catálogo, constituyen procesos insustituibles y vitales para desalinear la información que crece exponencialmente en relación a la obra del escritor chileno, como fuente energética y vital que abre una posibilidad de continuidad para un campo literario en crisis. Esto, no sólo porque es abundante y cuenta todavía con una cantidad considerable de material inédito, sino porque en ella la escritura y, más específicamente, el lenguaje, dan cuenta de una reflexión profunda sobre los principales problemas que afectan a los estudios literarios en la época actual y porque encuentra una forma nueva para la literatura que, a su vez, reclama nuevas formas para la crítica. En este sentido, consideramos que la obra de Bolaño resulta un desafío para los críticos de la literatura y para la reflexión teórica actual.

El “Archivo Bolaño 1977-2003” / Herederos de Roberto Bolaño (AHRB)5 comprende la publicación de un catálogo homónimo que, además de dar cuenta de la exposición en sí mediante la descripción y la incorporación de imágenes de los objetos exhibidos, incluye un total de ocho textos críticos y testimoniales inspirados en el autor y su obra.

Como se aprecia en la exposición del Archivo y se resalta en los distintos

${ }^{5}$ La exposición "Archivo Bolaño 1977-2003" se presenta en Barcelona entre el 5 de marzo y el 30 de junio de 2013 y, posteriormente, se traslada a Argentina para ser exhibida en el Centro Cultural Recoleta de Buenos Aires (CCR), entre el 19 de diciembre y el 16 de febrero de 2014. Es una producción del Centro de Cultura Contemporánea de Barcelona (CCCB) que surge como forma de homenaje, tras cumplirse diez años de la muerte del escritor chileno, y como testimonio visual y material de la potencia y vitalidad de su obra literaria, según lo expresan sus organizadores. Cabe enfatizar que tanto la exposición como el catálogo se llevan a cabo con la autorización y colaboración de Carolina López, en representación de los Herederos de Bolaño. El Archivo cuenta con la participación de Juan Insua y Valerie Miles, comisarios de la exposición, además de la colaboración de diversos prestadores de materiales originales, materiales de reproducción fotográfica y audiovisual e instaladores de originales, tanto de México como de España. Así también, el volumen impreso y la exposición en sí cuentan con el respaldo de las máximas autoridades de la diputación de Barcelona: Salvador Esteve I Figueras, presidente de la Diputación y del Consorcio del CCCB y, Marçal Sintes, director del CCCB. Este último, inicia el catálogo con el texto testimonial "Bolaño en Cataluña". Aquí, el director del CCCB hace presente su convencimiento del enorme atractivo que la exposición encierra y recalca que la motivación principal consiste en entregar un material valioso en varios sentidos, dada la importancia del autor y de su obra, así como también enfatiza el hecho innegable de que Bolaño pasa la mitad de su existencia en España, razón por la cual existe una vinculación directa y un compromiso con la figura del escritor y su legado. 
apartados del catálogo, los diversos materiales exhibidos dejan constancia de la existencia real del autor, permiten reconstruir segmentos de la biografía de Bolaño durante un período de 26 años en los que se materializa la mayor parte de su obra literaria, aspectos de los que la exposición da cuenta por medio de la inclusión de una serie de cuadernos, manuscritos originales, fragmentos, libros, cartas, notas de revistas, dibujos, fotografías, objetos personales y recortes de prensa.

En coherencia con nuestra experiencia real que sitúa la lectura del librocatálogo antes que la visión de la exposición, sintetizamos, en primer lugar, los aspectos más relevantes en relación al volumen Archivo Bolaño 19772003 (2013).

El libro presenta una serie de ocho textos, cada uno de ellos en un estilo diferente, pero con el común denominador de generar una atmósfera íntima, abordando el tema desde una perspectiva subjetiva.

El primer texto, "Vuelta al origen" (2013: 15-26), de Valerie Miles, comienza con un reconocimiento a Carolina López. De ella se destaca esa especie de genialidad práctica, reconociéndole una función decisiva en la creación de las condiciones de trabajo, la estabilidad y el espacio vital que la viuda aporta a la carrera de Bolaño, además de reconocer la generosidad en el cuidado del legado del escritor. En este apartado Miles incorpora una serie de textos que son parte del archivo y explica el complejo proceso de reconstitución de una cronología creativa, que implica, sin lugar a dudas, un delicado y trabajoso análisis de los materiales. En este sentido, destaca que el mayor atractivo de una muestra como ésta radica en la posibilidad de apreciar los manuscritos, ser testigos de "su extraordinariamente meticulosa caligrafía que tiene algo orgánico, conserva su aura todavía o por lo menos da rienda suelta a la imaginación del espectador" (2013: 18). Enfatiza la parte de la obra que corresponde a la escritura de Gerona, espacio en el que, a su juicio, Bolaño alcanzaría una especie de mayoría de edad, aislándose para hallar el rumbo y diseñar las estructuras que luego empieza a aplicar, dejando ver sus ideas sobre la fragmentación y el tiempo, para dar lugar al caleidoscopio. Luego, ese universo iría expandiéndose de manera orgánica, con un carácter no estático ni rígido, sino poético, cósmico $\mathrm{y}$, fundamentalmente, oculto.

A continuación, el catálogo incluye una cronología creativa del período comprendido entre 1979 y 2003 (2013: 28-29), que no incorpora los textos 
aún inéditos recuperados del ordenador de Bolaño, sino sólo los conocidos durante la vida del autor y los que han aparecido publicados de manera póstuma. La cronología también incluye materiales que corresponden a textos mecanografiados aún inéditos escritos hasta 1986, como es el caso de El espíritu de la ciencia ficción, Diorama o La virgen de Barcelona. Se organiza en términos temporales y espaciales de creación, presenta una lista de 40 títulos y precisa el lugar de creación: Barcelona, 10 títulos; Gerona, 10; Blanes, 20; asimismo, cada parte se organiza en relación a los años de escritura, dejando en claro qué títulos del listado permanecen aún inéditos.

Luego de la cronología, se ubica "El legado del apóstata" (2013: 31-44) de Juan Insua. Éste se refiere, en primer término, a la crisis de representación, especialmente en relación al género exposición, al colapso de los espacios del conocimiento propios de la modernidad y a las características de los nuevos espacios, aquellos que ocupan las prácticas creativas actuales. En el mismo sentido, se refiere al impacto de las tecnologías y los cambios que su desarrollo exponencial conlleva. Por ello, explica que la exposición surge como un espacio híbrido que intenta recrear el complejo universo creativo de Bolaño, incorporando apoyos tecnológicos, pero intentando mantenerse fiel a las características propias de éste.

Insua entrega, además, su visión del Archivo, de la obra y de los materiales que en ella se exhiben. Destaca la tenacidad del escritor, su voluntad de escribir desde una Universidad Desconocida cuyos pabellones intentan ser reconstruidos para los visitantes del Archivo y en cuyo proceso de montaje sobresale el carácter perturbador que adquiere la revisión de sus escritos. Acentúa el humor, muchas veces delirante, como elemento central en la obra de Bolaño y su bibliofilia salvaje de lector omnívoro, como él mismo se autodefine. Finalmente, hace énfasis en esa suerte de enigma que encierra la obra, que se impone y que se proyecta sobre el devenir de la literatura. "Corolario: hay que releer a Bolaño otra vez" (2013: 40).

Luego, se sitúa "RB/BCN 1977/1980" (2013: 43-51), texto en el que Antoni García Porta relata y evoca, a través de una escritura reflexiva y creativa, su recuerdo de Bolaño. Nos hace parte de su historia juntos, de cómo se conocieron, del arrojo que caracteriza a Bolaño y la desesperación que lo ronda, la falta de dinero que, a su juicio, no es lo mismo que la pobreza, destaca el convencimiento total que Bolaño tenía respecto de la única tarea por hacer, pues "sólo había que perseverar y escribir y escribir y leer y leer y 
que no había más, que no había más secreto" (2013: 43). La literatura como dedicación exclusiva. Recuerda los años en Barcelona, los inicios de Bolaño en las revistas que luego serían fanzines, destacando la dedicación total del escritor y el compromiso absoluto con la causa, la literatura, la única que lo movía a no dormir, a escribir de día y trabajar de noche, impulsado por una imaginación superlativa y experiencias reales extremas con la realidad. Recuerda también el interés supremo de Bolaño por la poesía y por la literatura, por los franceses, por saber qué sucedía en México, en Chile, en Latinoamérica. Destaca la nutrida correspondencia que el joven Bolaño mantiene con escritores y artistas de estos lugares, el admirable conocimiento de obras y autores, clásicos, marginales y otros, quizá, imaginarios.

En este texto, García Porta se refiere, además, a la singular personalidad del escritor, a quien caracteriza como "alguien que llevaba programado en el ADN el sello de agitador literario" (2013: 48). Recuerda las conversaciones encendidas, delirantes, las ideas excéntricas, todas ellas evocadas con la nostalgia de quien compartió directamente con Bolaño. Luego, hace una breve mención a su relación de coautoría que califica como una suerte de aprendizaje, pues lo que predomina, afirma, es una suerte de admiración por el fallecido escritor y una lealtad que subyace en las palabras y atraviesa cada línea del texto.

A continuación, encontramos el texto "Bolaño en Gerona: una amistad" (2013: 59-65), en el que Javier Cercas recuerda al escritor desde una dimensión afectiva, dejando ver una nostalgia similar, en algún sentido, al sentimiento que atraviesa las palabras de García Porta. Cercas recuerda el período final, la presencia inevitable de la enfermedad y la muerte. Asimismo, hace hincapié en el valor de la obra literaria del homenajeado y en la admiración que le genera, sobre todo, "por la furiosa radicalidad con que, desde que era un adolescente, había asumido su vocación de escritor" (2013: 63).

En un sentido similar, aparece el texto "Blanes o los escritores de antes" (2013: 81-97), de Enrique Vila-Matas, quien, en primer término, recuerda el momento en que Bolaño y él se conocieron, casualmente, justo después de la publicación de Estrella distante (1996). Hace presente que desde ese momento le pareció "estar frente a un escritor de verdad" (2013: 85), un escritor de antes, libre, sin la presión nefasta de las actuales reglas del mercado. Posteriormente, enfatiza, surge la amistad. Evoca las visiones de aquellos momentos íntimos en que compartían, familiarmente, expe- 
riencias cotidianas, como también acaloradas discusiones literarias. Luego, hace referencia al encierro y al silencio, es decir, al período en que Bolaño se haya aislado para dedicarse completamente a su obra, explica cómo fue la época de Blanes o de un samurái en Blanes. En este sentido, Vila-Matas agrega que, a veces piensa y le surge la impresión de que Bolaño tenía la literatura en la sangre. Reconoce que le compartió ideas tan significativas que, finalmente, ha hecho suyas para darse ánimos cuando las fuerzas se agotan y cita al propio Bolaño: "La literatura se parece mucho a la pelea de los samurai, pero un samurai no pelea contra otro samurai: pelea contra un monstruo. Generalmente sabe, además, que va a ser derrotado. Tener el valor, sabiendo previamente que vas a ser derrotado, y salir a pelear: eso es la literatura" (2013: 87). Un escritor de verdad, para quien el único poeta ha sido Mario Santiago y a quien su muerte trágica, como es sabido, afectó hondamente.

Vila-Matas reafirma la importancia de la etapa de anonimato, pues, a su juicio, "Bolaño no habría podido decir tantas cosas de no haber estado mudo durante todo ese tiempo" (2013: 84). De ese silencio brota una energía inagotable que hace posible la obra de Bolaño y que se hace conocida cuando ya fluye libre e imparablemente; es, según Vila-Matas, el momento "cuando al fin detectan a esa estrella que cae sin que nadie la mire" (2013: 87). Al respecto, trae a la memoria la rueda de prensa que se efectúa con motivo de la publicación de Estrella distante, en la cual Herralde presenta a su nuevo autor ante los periodistas e invitados y, al fin, Bolaño comienza a ser escuchado, rompiendo ese largo silencio. Recuerda una interrogación que en la rueda de preguntas le exponen sobre Chile y su modesta realidad y que, según Vila-Matas, desencadenó la palabra irrefrenable, frente a lo cual los periodistas parecían pescadores hipnotizados y a partir de ahí, señala Vila-Matas, Bolaño comienza a "soltar un largo monólogo, absolutamente fascinante, fuera del tiempo y del lugar, un monólogo sobre la disciplina, la marcialidad británica del ejército chileno. Creo que Bolaño, a partir de aquel minuto cuarenta, paró el tiempo. Recuerdo que en un momento determinado cerré los ojos y fue extraño, sentí entonces que era como si sus palabras fueran marciales de verdad y pesaran doble. Hoy no descarto que la implacable máquina del anonimato que había ido forjándose en Blanes en el tiempo de silencio estuviera cargando doblemente cada una de esas palabras" (2013: 88). 
En seguida, se incluye el texto "El poeta Roberto Bolaño" (2013: 109117), de Olvido García Valdés. Éste comienza con un largo epígrafe que enfatiza la valentía de quien asume el riesgo de ser poeta o ser perdedor, lo que para García Valdés va unido. Para ganar, Bolaño debe perder. La autora enfatiza que, a su juicio, una pulsión de muerte atraviesa los textos del escritor. Advierte que esto se manifiesta en la poesía de Roberto Bolaño y resulta una verdad, una certeza, en la medida en que, sabiamente, él está siempre consciente de que vida y muerte, que sueño y fracaso, van juntos. Luego, independiente del convencimiento total que ella manifiesta hacia la idea de que Bolaño es ante todo un poeta, aunque prefieran verlo como narrador y silencien al poeta, insiste en la invisibilidad del poeta para la crítica y para el público general y se pregunta cuál es el lugar que se le asigna a Bolaño en tanto poeta.

Luego, García Valdés aclara que Bolaño, como poeta, se sabe condenado al hambre y, en su opinión, esto explica la tendencia hacia la narrativa, confirmando un aspecto que la crítica también ha detectado. No obstante, destaca que Bolaño no renuncia a la poesía, pues la lógica de la obra de Bolaño es siempre poética, más allá de la prosa o el verso, es energía libre que logra fluir a través de "una escritura que conoce, sin embargo, el vacío, que sabe que nada hay debajo" (2013: 115).

A continuación, se sitúa el texto "Roberto Bolaño en Estados Unidos" (2013: 119-124), en el que Bárbara Epler se refiere a la explosiva irrupción de la obra de Bolaño en los Estados Unidos y al impacto que genera en el ámbito literario norteamericano. Junto con ello, aborda el tema de la traducción de la narrativa y la poesía del autor, a la que le reconoce el mérito de captar el estilo de la escritura. Destaca la acogida crítica que acompaña a la publicación de la obra en New Directions. Recuerda el momento en que miles de jóvenes hicieron colapsar el bar del East Village al celebrar la publicación de Los detectives salvajes: "Aquí en Estados Unidos fue más un tsunami que una marea ascendente" (2013: 121). Considera que, más allá de la calidad inmensamente superior de la escritura del autor, el mérito mayor radica en que, a su juicio, Bolaño logra que la literatura renazca y por ello, afirma Epler, encuentra un lugar también en los Estados Unidos.

Por último, se sitúa el texto "Política, estética y horror en la obra de Roberto Bolaño" (2013: 125-129). En él, Patricia Espinosa se refiere a Bolaño y a su obra a partir del "Primer Manifiesto Infrarrealista", escrito por Bolaño. 
Destaca el carácter subversivo del escritor y de sus escritos, pues ve en la literatura el territorio de la resistencia. De ahí que, frente a la derrota de las utopías, a la manifiesta crisis de la modernidad, a la imposición de las dictaduras y al fatalismo que domina en Latinoamérica, Bolaño opte por la itinerancia antes que la domesticidad sistémica, lo que constituye la base del pensamiento crítico que el escritor moviliza en su obra. Por último, Espinosa advierte en la obra de Bolaño "la perfección de una escritura" (2013: 129).

Luego de esta serie de trabajos, enfrentamos una nota biográfica de Roberto Bolaño y una nota de los autores, que se incluyen en el volumen, seguidas de una traducción de los textos al inglés (134-173), realizadas por Marta Hernández y Julie Wark. Así también, hacemos notar que el librocatálogo incorpora, a lo largo de sus 173 páginas, una serie de imágenes de la mayoría de los materiales que conforman la exposición.

Así, con las ideas transmitidas por el catálogo y en vista de que Chile no se hace parte del itinerario de la exposición, surge la necesidad de cruzar la Cordillera de los Andes para dar paso a la segunda parte de nuestro análisis, que consiste en una síntesis de las principales observaciones resultantes de nuestra experiencia directa con el Archivo.

Nos enfrentamos, en vivo, con los materiales que antes vimos como imágenes en el catálogo y con otros objetos que no se incluyen en el volumen (lentes ópticos del escritor, máquina de escribir, teclado del computador).

En primer término, destacamos el interés perturbador que nos provoca enfrentar el texto "Las fracturas de la realidad"6, que forma parte del mítico "Manifiesto Infrarrealista" (1977) que Patricia Espinosa cita en el apartado "Política, estética y horror en la obra de Roberto Bolaño". De manera específica, nos llama la atención el siguiente fragmento de la escritura de Bolaño, que leído de su propia caligrafía resulta aún más inquietante:

Hacemos circular el discurso libremente [...] desatarse de la burguesía, del aparato cultural y de la tradición que ese aparato crea o manipula,

${ }^{6}$ Este fragmento forma parte del texto manuscrito "Las fracturas de la realidad" en Rosa de fuego, Barcelona, 1977. Material observado en visita al Archivo Bolaño: 1977-2003 en Centro Cultural Recoleta, sala J (1977-1984) y sala C (1985-2003), Buenos Aires, febrero de 2014. 
para buscar sin cordones umbilicales en las fracturas de la realidad (Bolaño, 1977).

Observamos largamente la composición del escrito, contemplamos esa dimensión orgánica que destaca Miles en su trabajo y nos insinúa la perfección a la cual refiere Espinosa. Luego, espontáneamente, el texto nos sugiere una relación con unos de los fragmentos que componen las solapas de La nueva novela (1977) de Juan Luis Martínez, en relación a las fracturas de la realidad: "la re la re la realidad" o "a la re a la re a la realidad". En seguida, recordamos el texto “Unas pocas palabras para Enrique Lihn”, recogido en Entre paréntesis (2008), en el que Bolaño, parafraseando a Martínez, afirma: “Te queda la extraña sensación de que la literatura ha estado a la altura de la realidad. La famosa rea, la rea, la rea, la rea-li-dad" (2008: 202).

Luego, en el mismo texto, "Las fracturas de la realidad", observamos las características del discurso crítico de Bolaño, a través de una escritura reflexiva, crítica y creativa, que moviliza un pensamiento cuyo eje es la libertad. En este fragmento, deja en claro su desprecio hacia los sistemas reguladores y controladores del poder, los que rechaza abierta y directamente, entendiendo la literatura como espacio de insurrección y subversión, tal como lo destaca Patricia Espinosa, lo que se confirma a la luz de nuestro marco teórico. Así, continúa:

Esto siempre ha pasado en la literatura y en el arte del período capitalista y en las sociedades clasistas [...] es la lucha por el poder y el poder son las revistas, libros, premios, etc. (Bolaño, 1977).

La experiencia directa con el Archivo nos reafirma que Bolaño escribe como si caminara de espaldas a este funcionamiento sistémico del cual es profundamente crítico, tal como los jóvenes poetas real visceralistas, y de acuerdo a lo que Espinosa enfatiza también en el trabajo antes citado.

Seguimos avanzando y nos encontramos con un objeto del Archivo en que creemos que se condensa, de una forma distinta, la idea anterior. Se trata de la "Tarjeta de presentación" de Bolaño7. Ésta da cuenta, creati-

7 Cabe mencionar que nuestro conocimiento de este objeto real hasta ahora se limitaba a la imagen que aparece en $\mathrm{Du}, 819: 19$. 
vamente, de su posición de "poeta y vago", lo que desde nuestro marco teórico entendemos como la irrupción más directa del escritor escisionista, aquel que hace entrar el oficio de la escritura en un estilo de insurrección permanente, que se autodefine poeta y vago, es decir, inútil al sistema de trabajo moderno y capitalista, frente al cual reafirma su carácter libre. El objeto en sí nos resulta cada vez más sugerente y subversivo, permitiéndonos comprobar, de manera directa, lo que en muchos pasajes del catálogo se intenta transmitir.

El contacto real con la exposición es una experiencia insustituible y única que posibilita la visión de los materiales orgánicos y originales, nos enfrenta a los fragmentos de un proyecto de creación que nos parece valioso, porque lleva en sí y, de manera central, una respuesta crítica y creativa al estado de descomposición y al deterioro que impera en las distintas dimensiones del funcionamiento humano global. Frente a lo cual Bolaño busca resistir y traspasar el bloqueo mental que se impone mediante el nihilismo consumado que penetra todas las dimensiones de la existencia humana. Notamos que Bolaño genera una respuesta a partir de la literatura, privilegiando la libertad como elemento central y condición vital para la continuidad. Entonces, apreciamos que el texto contenido en el Manifiesto y la tarjeta de presentación constituyen distintas formas para una misma convicción, creer que, si no se entiende como una actividad superficial, la literatura permite elaborar un pensamiento libre y en oposición a lo falso que domina todas las dimensiones de la existencia.

Según afirma Meyronnis, actualmente, pensar significa luchar contra la imposibilidad de pensar y la energía para ello se encuentra en el lenguaje. En términos más amplios, considera que es posible postular una subversión, precisamente a partir de una experiencia extrema, desde donde emerge una libertad salvaje que posibilita la reflexión y la creación y desde donde surge el concepto escisionista que proponemos para entender y explicar la figura y el proyecto de Roberto Bolaño a la luz de su Archivo. Creemos que se trata del Archivo de un escisionista, en coherencia con la idea del poeta y vago. En este punto, conviene precisar que Meyronnis define el concepto a partir del pensamiento de Rimbaud, reactualizando la idea de horribles travailleurs que remite a aquellos horribles trabajadores que no temen salirse de lo establecido, más allá de razas, culturas o nacionalidades, plantea que se les podría llamar escisionistas por no admitir ninguna comunidad, 
problematizando el circuito de lo falso que domina todo. Asimismo define el acto escisionista como una forma de salir de la comunidad humana esclavizada y traspasar el nihilismo. Se trata de enfrentar el peligro o la extrema negatividad. El escisionista, afirma Meyronnis, se sitúa contra el sistema de la esclavitud y trabaja en el riesgo, a través de una escritura y reescritura constante, tal como notamos que lo hace Bolaño, a partir de los manuscritos exhibidos en su Archivo.

Así, creemos que Roberto Bolaño diseña una estrategia de resistencia y de continuidad, pues imagina un contraataque factible al poder y lo hace desde su obra, que, como la crítica literaria y el propio catálogo lo destaca, entra al mercado a través de la narrativa, sin renunciar a la poesía, por lo tanto, ingresa de manera subversiva, es decir, sin que éste logre desactivar la bomba de relojería que el poeta diseña durante toda su vida, o al menos en el transcurso de tres décadas, como consta en el Archivo. El mercado y sus operadores no dimensionan la magnitud del pensamiento que se moviliza, no perciben la conspiración que se trama e intentan hacer de Bolaño un nombre convertido en marca y de su obra un producto más de consumo, ubicado en el centro de la atención. Esto, en contraste total con la historia del escritor, la del poeta sistemáticamente rechazado, como lo deja claro, por ejemplo en el texto "Mi carrera literaria", incluido en La Universidad Desconocida (2007):

Rechazos de Anagrama, Grijalbo, Planeta, con toda seguridad / también de Alfaguara, Mondadori: Un no de Muchnik, / Seix Barral, Destino... Todas las editoriales /Todos los lectores / Todos los gerentes de ventas / Bajo el puente, mientras llueve, una oportunidad de oro / Para verme a mí mismo: / Como una culebra en el Polo Norte, pero escribiendo. / Escribiendo poesía en el país de los imbéciles. / Escribiendo con mi hijo en las rodillas. / Escribiendo hasta que cae la noche / Con un estruendo de los mil demonios. / Los demonios que han de llevarme al infierno, / Pero escribiendo (2007: 7-8).

De este modo, reconocemos en la exposición, uno a uno, los textos que conforman las páginas del catálogo, hasta que de pronto nos enfrentamos a una serie nueva. Aquí, captura nuestra atención una carta. En ese instante nos detenemos a observar. Se trata de un texto que ayuda a confirmar la 
relación epistolar que, según el testimonio de los cercanos al escritor, Bolaño mantuvo con distintos escritores y amigos. En este caso, se trata de una carta de Enrique Lihn. El manuscrito es una respuesta dirigida a Bolaño, con fecha 28 de junio de 1983. La leemos en silencio, observamos la caligrafía del poeta, el soporte, todo muy bien cuidado, nos permite entrever las marcas que el paso del tiempo imprime en el escrito. Hay alusión a una lectura poética realizada en nuestro país, donde según se refiere, fueron leídos algunos textos de Bolaño, que según afirma Lihn: "interesaron mucho". Luego, nuestra vista se queda con la última frase, una idea con la que se cierra la carta y se da paso a la despedida: “Todo aquí una calamidad”. En este punto nos preguntamos a qué alude, específicamente, con esta frase final. ¿Por qué Lihn emplea el concepto de “calamidad”?, ¿será para referirse a la realidad chilena de 1983? No lo podemos asegurar. Luego, inevitablemente, nos ponemos a pensar qué pasa con Chile en la situación actual.

Finalmente, en nuestra visita al Archivo percibimos que se presenta a Bolaño como uno de los grandes escritores que forma parte del horizonte de referencia cultural y cuya exposición contribuye a reflexionar sobre temas de relevancia para el presente y el futuro. Se repite el dato en la biografía: Roberto Bolaño nace en Chile en 1953. Hay, en el Archivo, una carta de puño y letra de Enrique Lihn, un referente constante en su obra, poeta chileno fundamental, como el mismo Bolaño se encarga de dejar en claro; sin embargo, notamos una falta de protagonismo de Chile en relación al tema. A raíz de lo anterior, resulta interesante volver al catálogo, específicamente, a un fragmento del texto ubicado en sus páginas introductorias: "es de justicia que el CCCB le rinda un homenaje que abre nuevas perspectivas sobre su legado". En virtud de la misma lógica, nos llama poderosamente la atención que en honor a la justicia no se rescate la parte chilena de Bolaño. Es llamativo que no se incorporen mayores referentes reales anteriores a 1977. Por lo tanto, podemos concluir que hay 24 años pendientes, en relación a los cuales persiste el misterio. Creemos que hay un archivo que falta en relación a la infancia, adolescencia y juventud de Bolaño, a su relación con el proyecto de la Unidad Popular, a su detención en 1973.

Para cerrar, confirmamos que la aproximación al "Archivo Bolaño 19772003" permite franquear la barrera de lo falso y trazar nuevas líneas de continuidad hacia dimensiones inexploradas aún por la crítica especiali- 
zada en la obra de Bolaño, a quien entendemos como un escisionista que diseña una estrategia para dar continuidad a la literatura. Por lo tanto, hay que releerlo, sobre todo en Chile; parafraseando a Bolaño, es tarea urgente.

\section{Referencias}

Badré, F. (2003). L'avenir de la littérature. Paris: Gallimard.

Bolaño, R. (1977). Las fracturas de la realidad. En Rosa de fuego, Barcelona. Material observado en visita al Archivo Bolaño: 1977-2003 en Centro Cultural Recoleta, sala J (1977-1984) y sala C (1985-2003), Buenos Aires, febrero de 2014 .

(1996). Estrella distante. Barcelona: Anagrama.

(2007). La Universidad Desconocida. Barcelona: Anagrama. (2008). Entre paréntesis. Barcelona: Anagrama. (2010). El tercer Reich. Barcelona: Anagrama. (2011). Los sinsabores del verdadero policía. Barcelona: Anagrama. (2013). Archivo Bolaño 1977-20o3. Barcelona: Centro de Cultura Contemporánea y Diputación de Barcelona.

Cercas, J. (2013). Bolaño en Gerona: una amistad. En Archivo Bolaño 19772003 (pp. 59-65). Barcelona: Centro de Cultura Contemporánea y Diputación de Barcelona.

Echevarría, I. (2013). El Archivo Bolaño. “Artes y Letras”, El Mercurio, 31 de marzo, E14.

Epler, B. (2013). Roberto Bolaño en Estados Unidos. En Archivo Bolaño 19772003 (pp. 119-124). Barcelona: Centro de Cultura Contemporánea y Diputación de Barcelona.

Espinosa, P. (2013). Política, estética y horror en la obra de Roberto Bolaño. En Archivo Bolaño 1977-2003 (pp. 125-129). Barcelona: Centro de Cultura Contemporánea y Diputación de Barcelona.

García, M. (2013). El Bolaño más íntimo. “Artes y Letras”, El Mercurio, 10 de marzo, E4-E5.

García Porta, A. (2013). RB/BCN 1977/1980. En Archivo Bolaño 1977-2003 (pp. 43-51). Barcelona: Centro de Cultura Contemporánea y Diputación de Barcelona.

García Valdés, O. (2013). El poeta Roberto Bolaño. En Archivo Bolaño 19772003 (pp. 109-117). Barcelona: Centro de Cultura Contemporánea y Diputación de Barcelona.

Guerrero, P. P. (2013). Festín para lectores de Bolaño. “Artes y Letras”, El Mercurio, 9 de junio, E14.

Houellebecq, M. (2011). Intervenciones. Barcelona: Anagrama. 
Houellebecq, M. y Lévy, B. H. (2010). Enemigos públicos. Barcelona: Anagrama.

Insua, J. (2013). El legado del apóstata. En Archivo Bolaño 1977-2003 (pp. 31-44). Barcelona: Centro de Cultura Contemporánea y Diputación de Barcelona.

Lanier, J. (2012). No somos computadoras. Buenos Aires: Debate.

Martínez, J. L. (1977). La nueva novela. Santiago: Ediciones Archivo.

Meyronnis, F. (2003). L’Axe du Néant. Paris: Gallimard.

Miles, V. (2013). Vuelta al origen. En Archivo Bolaño 1977-20o3 (pp. 15-26). Barcelona: Centro de Cultura Contemporánea y Diputación de Barcelona.

Oyarce Orrego, A. (2012). Cortes estratigráficos en la crítica y en la obra de Roberto Bolaño. Acta Literaria, 44, 9-33.

Revista $D u, 819$, septiembre de 2011.

Serrano Marín, V. (2007). Nihilismo y fin de la historia. Una mirada sobre la cuestión de la postmodernidad. Revista de Filosofía, 24, 5-44.

Vila-Matas, E. (2013). Blanes o los escritores de antes. En Archivo Bolaño 1977-2003 (pp. 81-97). Barcelona: Centro de Cultura Contemporánea y Diputación de Barcelona. 